\title{
IMPLEMENTASI ALAT PERONTOK JAGUNG DIDESA LODALEM KABUPATEN MALANG
}

\author{
Mujiono'), Sujianto ${ }^{2)}$ Munasih' $^{3)}$ \\ 1) ${ }^{2)}$ Teknik Industri, Institut Teknologi Nasional Malang \\ 3) Teknik Sipil, Institut Teknologi Nasional Malang \\ jiono1864@gmail.com.
}

\begin{abstract}
Abstrak.Tim pengabdian kepada masyarakat telah melakukan survey ke Petani jagung di desa LodalemKabupaten Malang Dengan tujuan untuk mendapatkan informasi dari petani tentang permasalahan yang dihadapi petani, pada saat panen jagung. Permasalahan yang dihadapi oleh petani adalah apabila jagung telah dipanen kemudian dijemur maka proses berikutnya adalah untuk dilakukan perontokan/pemipilan, hal ini masih dilakukan dengan menggunakan alat manual/seadanya misalkan dengan pemipilan dengan menggunakan tangan,kerok yang dibuat dari bambu, papan kayu dengan ban bekas, dll. Sehingga akan mengakibat mengeluarkan tenaga yang banyak/berlebihan serta dalam waktu yang cukup lama untuk melakukan perontokan/pemipilan,dengan keterbatasan alat mengakibatkan kurang baiknya biji jagung hasil pemipilan atau biji jagung banyak yang rusak, pecah dlsb, demikian juga akan mengakibatkan banyaknya waktu untuk menyelesaikan. Dari fakta dan kondisi di atas maka target dari pada pengabdian kepada masyarakat ini adalah untuk membuatkan alat perontok jagung dengan menggunakan kaidah ergonomis, agar supaya dapat mempercepat dan mempermudah pekerjaan pemipilan, menghemat waktu lebih efisien serta hasilnya lebih baik (hasil pipilan biji jagung ) dari yang sebelumnya. Adapun metode pelaksanaan yaitu melakukan pengembangan,memperbaiki proses perontokan/pemipilan dengan cara membuatkan alat yang lebih ergonomis sehingga jumlah pipilan lebih berkualitas, alat yang dipergunakan lebih menarik aman dan nyaman dipakai serta dapat meningkatkan hasil pemipilan dari $12 \mathrm{~kg} /$ jam menjadi $31 \mathrm{~kg} / \mathrm{jam}$.
\end{abstract}

Kata kunci : desain,ergonomis, produktif

\section{PENDAHULUAN}

Petani jagung yang berlokasi didesa lodalem kecamatan kalipare kabupaten malang ini adalah merupakan salah satu petani jagung terbesar yang ada di Kabupaten Malang. Jagung merupakan bahan makanan pokok selain beras. Jagung yang bermutu tinggi merupakan bahan baku yang dapat dioleh menjadi beragam produk industry makanan, diantaranya dapat diolah menjadi sirup, minyak nabati, tepung maizena, serta aneka makanan kecil (marning jagung,emping jagung,ciki dll)

Agar supaya dapat mendapatkan biji jagung yang bagus maka penangannannyapun harus dilakukan dengan bagus juga agar supaya hasil yang diperoleh bagus, maka perlu sarana dan prasarana yang memadai, yang mana selama ini hasil panen jagung, menurut hasil studi lapangan yang kami lakukan dalam memipil jagung masih menggunakan cara manual sehingga hasilnya masih belum optimal, waktu kerja yang panjang dan juga menyebabkan mudah mengalami kelelahan, untuk itu kami membuatkan alat perontok/pemipil jagung dengan kaidah ergonomis agar supaya dapat melakukan perontokkan jagung dengan aman dan nyaman serta tidak mudah lelah dan pada akhirnya dapat menghasilkan biji jagung yang baik.

Melihat kondisi di atas maka Tim pengabdian kepada masyarakat membuatkan alat perontok jagung kepada petani agar dapat mempercepat dan mempermudah pekerjaan, menghemat waktu lebih efisien serta hasilnya lebih baik dan tidak pecah / retak seperti sebelumnya. 
Data Antropometri yang Digunakan dalam Perancangan

Kesimpulan yang dapat diambil adalah data antropometri akan menentukan bentuk, ukuran dimensi yang tepat berkaitan dengan produk tersebut dari populasi terbesar yang akan menggunakan produk hasil rancangan. Secara umum $90 \%$ - $95 \%$ dari populasi target dalam kelompok pemakaian suatu produk harus dapat digunakan secara layak dengan menggunakan operator seperti dibawah [3]

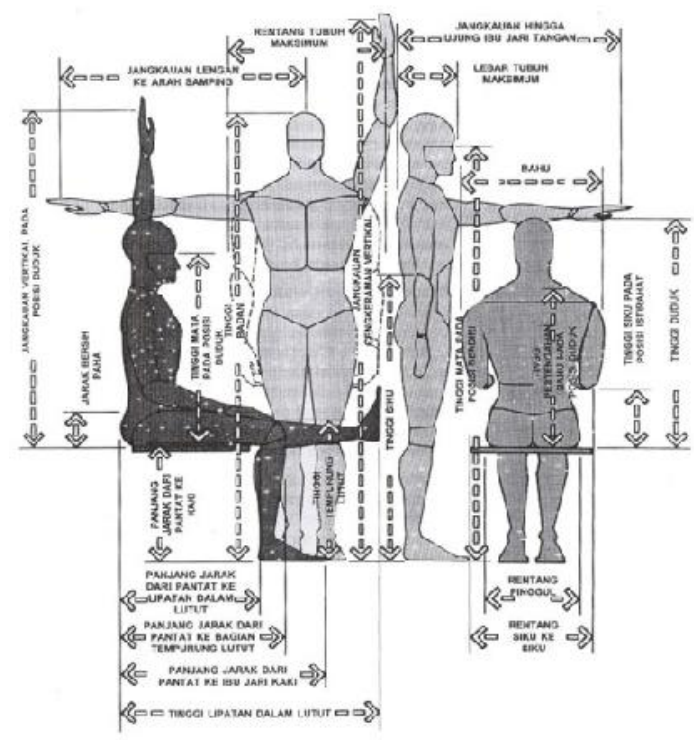

Gambar 4.5.1

Ukuran Macam-macam Antropometri

(Sumber: Julius Panero dan Martin Zelnik, Human Factor Dimension \& Interior Space)

\section{Waktu Standart}

Waktu standart bisa diperoleh dengan menambahkan kelonggaran atau allowance pada waktu normal, secara matematis sebagai berikut:

$\mathrm{Wb}=\mathrm{Wn} \times \frac{100 \%}{100 \%-\text { allowance }(\%)}$

$$
O_{s}=\frac{1}{W_{b}}
$$

Dimana: Ws $=$ Waktu Standart, $\mathrm{Wn}=$ Waktu Normal, $\mathrm{Wb}=$ Waktu Baku Os = Output standart[1]

\section{HASIL DAN PEMBAHASAN}

\section{Pembahasan}

Aktifitas perontokan jagung dengan menggunakan alat lama/manual hasilnya kurang baik yaitu hasilnya banyak yang pecah-pecah dan juga kurang ergonomis bagi operator/pemipil yang dialami adalah mudah capek dan juga hasilnya kurang maksimal seperti yang dilakukan oleh operator dengan cara antara lain seperti dibawah :

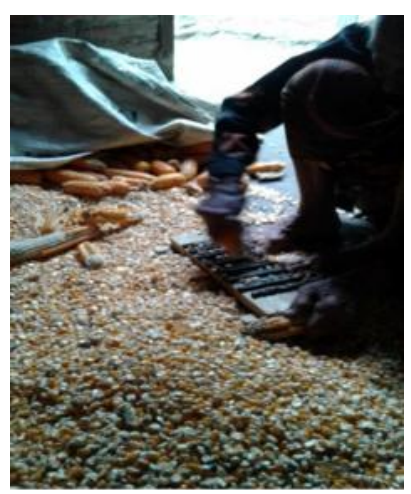


Sedang aktifitas yang dilakukan setelah hasil perancangan/hasil desail dapat mempermudah operator dan dapat dilakukan dengan secara ergonomis yaitu aman dan nyaman digunakan serta dapat mengahasil hasil yang baik yaitu biji jagung tidak pecah pecah seperti dibawah :

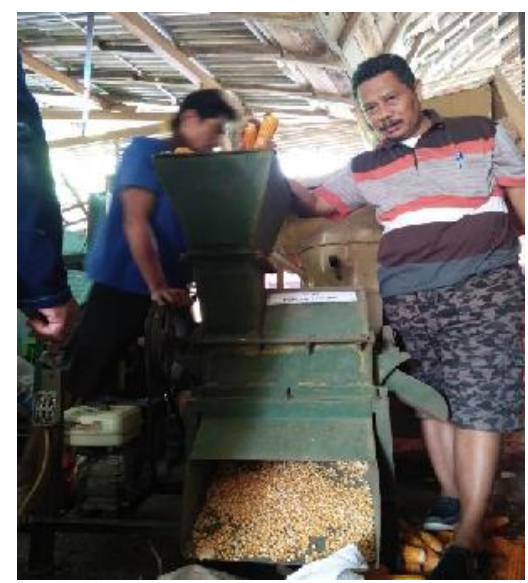

\section{Spesifikasi Alat}

1. Konstruksi rangka : Bentuk kotak dengan dasar segiempat dengan panjang $51 \mathrm{~cm}$,lebar $44 \mathrm{~cm}$,tinggi 60 $\mathrm{cm}$ dengan bahan besi siku ukuran 6 $\mathrm{cm}$.

2. Plat Pisau : Dengan panjang 40 $\mathrm{cm}$,lebar $6 \mathrm{~cm}$, ebal $2 \mathrm{~mm}$,jumlah 4 plat dn bahan besi plat

3. Penutup :Panjang $45 \mathrm{~cm}$,lebar $36 \mathrm{~cm}$, jari jari $18 \mathrm{~cm}$ dengan bahan besiplat

4. Saringan : dengan panjang 40 $\mathrm{cm}$,lebar $30 \mathrm{~cm}$, dan bahan beton asser

5. Corong : panjang atas $44 \mathrm{~cm}$, lebar atas $31 \mathrm{~cm}$, panjang bawah $25 \mathrm{~cm}$, lebar bawah $10 \mathrm{~cm}$, dengan bahan besi plat

6. Kecepatan $31 \mathrm{~kg} / \mathrm{jam}$

7. Hasilperbandingan:

\begin{tabular}{|l|l|l|l|}
\hline No. & \multicolumn{1}{|c|}{ Jenis Pembanding } & \multicolumn{1}{|c|}{ Alat manual } & \multicolumn{1}{c|}{ Alat hasil Rancangan } \\
\hline 1. & $\begin{array}{l}\text { Kemudahan } \\
\text { operasional }\end{array}$ & $\begin{array}{l}\text { Memerlukan banyak tenaga } \\
\text { dengan waktu yang lama }\end{array}$ & $\begin{array}{l}\text { Memerlukan sedikit tenaga } \\
\text { dan sedikit waktu }\end{array}$ \\
\hline 2. & Sistem Kerja & $\begin{array}{l}\text { Merontokkan jagung } \\
\text { dengan memutar jagung } \\
\text { pada alat sambil didorong }\end{array}$ & $\begin{array}{l}\text { Merontokkan jagung dengan } \\
\text { mesin menggunakan dynamo } \\
\text { untuk memutar pisau perontok }\end{array}$ \\
\hline 3. & Posisi kerja & Duduk dan jongkok & berdiri \\
\hline 4. & Waktu standar & 43.4 menit $/ 5 \mathrm{~kg}$ & $1.8 \mathrm{menit} / 5 \mathrm{~kg}$ \\
\hline 5. & Output standar & $12 \mathrm{~kg} / \mathrm{jam}$ & $31 \mathrm{~kg} / \mathrm{jam}$ \\
\hline
\end{tabular}

\section{Pembahasan}

Waktu Perontokan Jagung dengan menggunakan alat hasil perancangan. Selanjutnya dilakukan perhitungan WaktuSiklus ( Ws)

$$
\begin{aligned}
& N \quad=30 \\
& \sum x_{i}=38.4 \\
& W s \quad=\frac{\sum x_{i}}{N}=\frac{38.4}{30}=1.27 \quad \text { menit }
\end{aligned}
$$

Sedangkan besarnya Waktu Normal ( Wn) :

$$
\begin{aligned}
W n & =W s \times P \\
& =1.27 \times 1.11 \\
& =1.41 \text { menit } / 5 \mathrm{~kg}
\end{aligned}
$$

Besarnya waktu baku (Wb) adalah :

$$
\begin{aligned}
W b & =W n \times \frac{100 \%}{100 \%-\text { Allowance } \%} \\
& =1.41 \times \frac{100 \%}{100 \%-29 \%} \\
& =1.9 \text { menit } / 5 \mathrm{~kg}
\end{aligned}
$$


Maka besar output standart (Os) :

$$
\begin{aligned}
\text { Os } & =\frac{1}{W b}=\frac{1}{1.9} \\
& =0.52 \mathrm{~kg} / \text { menit } \\
& =31 \mathrm{~kg} / \mathrm{jam}
\end{aligned}
$$

\section{KESIMPULAN}

Dari hasil analisis data yang dilakukan oleh tim abdimas dapat disimpulkan seperti dibawah :
a. Hasil desain digunakan lebih aman dan nyaman dan efisien, effektif serta dapat meningkatkan hasil pemipilan
b. Alat didesain dengan menggunakan ukuran antropometri
c. Alat ini dapat lebih produktif dari 12 $\mathrm{kg} / \mathrm{jam}$ menjadi $31 \mathrm{~kg} / \mathrm{jam}$

\section{DAFTAR PUSTAKA}

[1]. Akao, Yoji. 1998. Quality Function Deployment: Intergrating Customer Requirement into Product Design. Oregon: Productivity Press.

[2]. Arikunto, Suharsimi, 2002,Prosedur Penelitian, Rhineka Cipta, Jakarta

[3]. Betts John E, 1983, Element of Applied Physics, reston, USA

[4]. Cohen, Lou, 1995. Quality Function Deployment "How to Make QFD Work for You".Addison-Wesley Publishing Company One Jacob Way.

[5]. Yarns. Technology,Structure and Applications.John Wiley \& Sons.New York

[6]. Nurmianto Eko, 2004, Ergonomi Konsep Dasar dan Aplikasinya, Edisi ke-2, Surabaya

[7]. Nigel Cross, 1996, Engineering Design Methods (Strategies For Product Design) Second Edition. 